\title{
Moderne Hard- und Softwarelösungen für präzise Diagnostik und effiziente Behandlungsmethoden
}

Morita bietet mit hochauflösenden Röntgensystemen, komfortablen Behandlungseinheiten und zuverlässigen Instru-

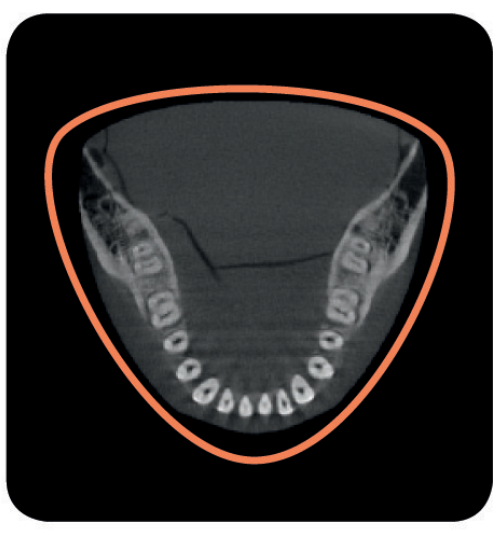

menten

effektive

Lösungen

für den

endodon-

tischen

Therapie-

ablauf an.

Ergän-

zend $\mathrm{zu}$

den Diag-

nosegerä-

ten sorgt

Moritas

smarte

Soft-

warelösung i-Dixel für eine lückenlose Dokumentation und einfache Bildverwal- tung: Dazu zählt neben vielseitigen Möglichkeiten zur Bearbeitung auch die umfangreiche Aufklärung des Patienten. Denn Diagnose, Behandlungsplanung und der gesamte Verlauf der endodontischen Therapie lassen sich am Monitor visualisieren - ein weiterer Schritt auf dem Weg zur digitalisierten Praxis. Für endodontische Praxen lässt sich festhalten: Ob modernste Röntgendiagnostik, ergonomische Arbeitsplätze, hochwertige Instrumente oder zukunftsorientierte Laserverfahren - für jeden endodontischen $\mathrm{Ar}$ beitsschritt stellt das Unternehmen intelligente Lösungen bereit, die einzeln überzeugen können und in einem übergreifenden Gesamtkonzept aufgehen.

Nach einer Pressemitteilung der J. Morita Europe GmbH, Dietzenbach www.morita.com/europe 